\title{
Qualidade da carne de ovinos terminados em confinamento com dietas com silagens de diferentes cultivares de sorgo
}

\author{
[Meat quality of finishing feedlot lambs fed diets of assorted sorghum cultivars] \\ G.C. Gois ${ }^{1}$, E.M. Santos ${ }^{1}$, W.H. Sousa ${ }^{2}$, J.P.F. Ramos ${ }^{2}$, P.S. Azevedo ${ }^{1}$, J.S. Oliveira ${ }^{1}$, \\ G.A. Pereira ${ }^{1}$, A.F. Perazzo ${ }^{1}$ \\ ${ }^{1}$ Universidade Federal da Paraíba - UFPB - Areia, PB \\ ${ }^{2}$ Empresa Estadual de Pesquisa Agropecuária da Paraíba- Emepa - João Pessoa, PB
}

\begin{abstract}
RESUMO
Objetivou-se avaliar a influência de dietas contendo silagem de diferentes cultivares de sorgo sobre as características físicas e químicas na carne de ovinos sem padrão racial definido, com idade entre cinco e sete meses e peso vivo médio de $17,7 \pm 3,7 \mathrm{~kg}$, alimentados com dietas contendo silagem de diferentes cultivares de sorgo. O experimento foi conduzido na Estação Experimental Pendência, pertencente à Empresa Estadual de Pesquisa Agropecuária - Emepa, tendo um período experimental de 42 dias. Utilizou-se um delineamento inteiramente ao acaso, com cinco tratamentos (silagem de sorgo BRS 610, BRS 655, BRS 800, BRS 810 e Ponta Negra) e sete repetições. Ao atingirem o peso de abate de $26,24 \mathrm{~kg}$, os animais foram encaminhados ao abate. Procedeu-se à análise do $\mathrm{pH}$, da cor, da perda de peso por coç̧ão, da força de cisalhamento, bem como à determinação de umidade, proteínas, cinzas e lipídeos totais no músculo Longissimus dorsi. As dietas não influenciaram os parâmetros de $\mathrm{pH}(5,64)$, cor $\left(\mathrm{L} * 23,13, \mathrm{a}^{*} 18,00, \mathrm{~b}^{*} 15,78\right)$, perdas de peso por cocção $(34,43 \%)$, umidade $(72,53 \%)$, proteína $(24,08 \%)$, cinzas $(1,09 \%)$ e lipídeos $(2,99 \%)$. A força de cisalhamento diferiu entre as dietas, com a silagem do cultivar BRS 655 propiciando uma carne mais macia $\left(2,10 \mathrm{kgf} / \mathrm{cm}^{2}\right)$. As silagens de sorgo utilizadas na confecção das dietas de cordeiros em confinamento não interferem nas características de qualidade da carne de ovinos sem padrão racial definido. Dietas contendo silagem de sorgo granífero BRS 655 proporcionaram uma carne mais macia.
\end{abstract}

Palavras-chave: força de cisalhamento, cor, gordura, maciez, proteína

\begin{abstract}
This study aimed to evaluate the influence of diets containing silage of different sorghum cultivars on the physical and chemical characteristics in the meat of lambs. Thirty five animals of undefined breed with average age between 5 and 7 months and average body weight of $17.7 \pm 3.7 \mathrm{~kg}$ were used. The lambs were randomly assigned to five treatments (sorghum silage BRS 610, BRS 655, BRS 800, BRS 810 e Ponta Negra) with seven replicates. When they reach $26.24 \mathrm{~kg}$ of weight, the animals were sent to be slaughtered. Proceeded to the analysis of $\mathrm{pH}$, color, cooking losses, shear force, determination of humidity, protein, ash and total amount of lipids in the Longissimus dorsi. The diets did not influence the parameters of $p H$ (5.64), color (L*23.13, $\left.a^{*} 18.00, b * 15.78\right)$, cooking losses (34.43\%), humidity (72.53\%), protein (24.08\%), ash (1.09\%) or lipids (2.99\%). The shear force differed among the diets, with the silage of cultivar BRS 655 providing a tender meat $\left(2.10 \mathrm{kgf} / \mathrm{cm}^{2}\right)$. The sorghum silages used in in the diets did not interfere in the meat quality characteristics of feedlot lambs. Diets containing sorghum grain silage BRS 655 provided a tender meat.
\end{abstract}

Keywords: color, fat, flavor, protein, tenderness

Recebido em 7 de junho de 2016

Aceito em 4 de fevereiro de 2017

E-mail: glayciane_gois@yahoo.com.br 


\section{INTRODUÇÃO}

A determinação da qualidade da carne vem se tornando cada vez mais objetiva, respaldada em testes químicos e físicos, uma vez que é uma combinação dos atributos sabor, suculência, textura, maciez e aparência, associados a uma carcaça com pouca gordura, muito músculo e preços acessíveis. Tejeda et al. (2008) mencionaram que a qualidade e aceitabilidade da carne de cordeiros é determinada pelas características físicas e químicas, as quais incluem o teor e a composição de gordura, bem como seus aspectos sensoriais.

O uso de silagem pode contribuir para elevar a produtividade animal e a rentabilidade dos sistemas produtivos. O sorgo é bastante usado para silagem, podendo ser utilizado em diferentes sistemas de produção de forragem, principalmente por apresentar baixo custo de produção, possibilidade de aproveitamento da rebrota, maior amplitude de época de plantio, além de sua resistência ao déficit hídrico e às altas temperaturas (Machado et al., 2011). Em condições semiáridas, o uso de silagem de sorgo pode amenizar o problema de escassez de forragem, permitindo a intensificação da produção, pela terminação de ovinos em confinamento. No entanto, é importante avaliar se as diferenças no valor nutritivo dos cultivares, decorrentes de divergências agronômicas, podem afetar o valor nutritivo da dieta e, dessa forma, a qualidade da carne de ovinos confinados.

As características físico-químicas são as que afetam diretamente o mercado, estando submetidas a diversos fatores de variação ante mortem e post mortem, muitos deles ainda desconhecidos, sendo oportuno estudar a influência da dieta sobre a qualidade da carne, uma vez que o seu conhecimento permitirá melhorá-las. Nesse contexto, objetivou-se avaliar a composição físico-química da carne de cordeiros sem padrão racial definido, alimentados com dietas contendo silagem de diferentes cultivares de sorgo.

\section{MATERIAL E MÉTODOS}

O experimento foi conduzido na Estação Experimental de Pendência, pertencente à Empresa Estadual de Pesquisa Agropecuária da
Paraíba S.A. (Emepa-PB). Trinta e cinco cordeiros machos, não castrados, sem padrão racial definido (SPRD), com idade entre cinco e sete meses e peso vivo inicial médio de $17,7 \pm 3,7 \mathrm{~kg}$, foram distribuídos em cinco tratamentos constituídos por dietas contendo silagens de diferentes cultivares de sorgo e sete repetições. Os cultivares de sorgo utilizados na confecção das silagens foram BRS 610 (duplo propósito), BRS 655 e BRS 800 (graníferos), BRS 810 e Ponta negra (forrageiros).

As dietas (Tab. 1) foram formuladas para um ganho diário de 200g/dia (Nutrient..., 2007). A ração e a água foram oferecidas ad libitum, duas vezes ao dia (às $7 \mathrm{~h} 30$ e às 15h30). As sobras foram colhidas e pesadas para determinação do consumo e ajuste da ingestão de MS, de forma a permitir $10 \%$ de sobra no cocho.

O consumo voluntário de matéria seca foi calculado mediante a diferença entre as quantidades oferecidas e as sobras. O consumo de nutrientes digestíveis totais $(\mathrm{CNDT})=(\mathrm{PB}$ ingerida $-\mathrm{PB}$ fecal $)+2,25 *(\mathrm{EE}$ ingerido $-\mathrm{EE}$ fecal $)+($ FDN ingerido - FDN fecal $)+(\mathrm{CNF}$ ingerido $-\mathrm{CNF}$ fecal) e o \%NDT $=($ consumo de NDT / consumo de MS)*100, segundo a recomendação de Sniffen et al. (1992).

Os cordeiros foram alojados em baias individuais com livre acesso aos comedouros e bebedouros, onde permaneceram por 42 dias em avaliação, precedidos de 11 dias de adaptação, sendo abatidos com peso corporal médio de $26,24 \mathrm{~kg}$. Para se determinar o ganho de peso total (GPT), os animais foram pesados no início e no final de cada período experimental. Previamente ao abate, os animais foram submetidos a jejum sólido e dieta hídrica por um período de 16 horas. O método de abate adotado foi o do atordoamento com concussão cerebral. As carcaças foram lavadas, pesadas e refrigeradas em câmara frigorífica a $4^{\circ} \mathrm{C}$, por 24 horas.

Foram coletadas amostras do músculo Longissimus dorsi da região dorsolombar, seccionado na altura da $10^{\mathrm{a}}$ à $13^{\mathrm{a}}$ costela. Em seguida, as amostras foram individualmente embaladas, identificadas e armazenadas a $-20^{\circ} \mathrm{C}$ até o início das análises. 
Qualidade da carne...

Tabela 1. Composição bromatológica das dietas experimentais

\begin{tabular}{|c|c|c|c|c|c|}
\hline & \multicolumn{5}{|c|}{ Silagens de sorgo } \\
\hline & BRS & BRS & BRS & BRS & \multirow{2}{*}{ Ponta Negra } \\
\hline & 610 & 655 & 800 & 810 & \\
\hline Ingredientes, $\%$ na MS & \multicolumn{5}{|c|}{ Proporção dos ingredientes (\%MS) } \\
\hline Silagem & 45,11 & 49,62 & 50,98 & 50,85 & 50,15 \\
\hline Milho & 39,07 & 37,83 & 36,25 & 36,18 & 34,66 \\
\hline Farelo de soja & 11,17 & 8,05 & 8,38 & 8,59 & 10,80 \\
\hline Ureia & 0,69 & 0,63 & 0,62 & 0,62 & 0,64 \\
\hline Cloreto de amônio & 1,01 & 0,93 & 0,90 & 0,90 & 0,81 \\
\hline Sal mineral $^{1}$ & 2,06 & 2,14 & 2,06 & 2,07 & 2,02 \\
\hline \multirow{2}{*}{ Calcário } & 0,89 & 0,81 & 0,81 & 0,79 & 0,92 \\
\hline & \multicolumn{5}{|c|}{ Composição química (\%MS) } \\
\hline Matéria seca & 38,16 & 41,70 & 40,91 & 40,64 & 39,09 \\
\hline Matéria orgânica & 89,52 & 90,25 & 90,35 & 90,19 & 90,72 \\
\hline Matéria mineral & 10,48 & 9,75 & 9,65 & 9,81 & 9,28 \\
\hline Proteína bruta & 16,54 & 16,61 & 16,40 & 16,71 & 16,29 \\
\hline Fibra em detergente neutro & 29,61 & 28,77 & 29,77 & 29,94 & 32,93 \\
\hline Carboidratos não fibrosos & 45,17 & 46,91 & 46,73 & 45,37 & 42,30 \\
\hline Carboidratos totais & 74,78 & 75,69 & 76,51 & 75,32 & 75,23 \\
\hline Extrato etéreo & 4,54 & 4,79 & 4,06 & 4,91 & 5,27 \\
\hline
\end{tabular}

${ }^{1}$ Suplemento mineral (nutriente/kg de suplemento): vitamina A 135.000,00UI.; vitamina D3 68.000,00UI.; vitamina E 450,00UI.; cálcio $240 \mathrm{~g}$; fósforo $71 \mathrm{~g}$; potássio $28,2 \mathrm{~g}$; enxofre $20 \mathrm{~g}$; magnésio $20 \mathrm{~g}$; cobre $400 \mathrm{mg}$; cobalto $30 \mathrm{mg}$; cromo $10 \mathrm{mg}$; ferro $2.500 \mathrm{mg}$; iodo $40 \mathrm{mg}$; manganês $1.350 \mathrm{mg}$; selênio $15 \mathrm{mg}$; zinco $1700 \mathrm{mg}$; flúor máximo $710 \mathrm{mg}$; solubilidade do fósforo (P) em ácido cítrico a $2 \%$ ( $\mathrm{min}$.). Excipiente q.s.p. - 1,000g.

$\mathrm{O}$ valor do $\mathrm{pH}$ da carne foi mensurado à zero hora e às 24 horas após o abate, usando-se um pHmetro portátil. A avaliação da cor da carne foi realizada com auxílio de um colorímetro MINOLTA CR300 (Precise, 1998), operando no sistema CIELAB $\mathrm{L}^{*}$ (luminosidade), $\mathrm{a}^{*}$ (intensidade de vermelho) e $b^{*}$ (intensidade de amarelo), calibrado com placa de cerâmica branca, utilizando o iluminante $\mathrm{C}, 10^{\circ}$ para a observação padrão. Para determinação da perda de peso por cocção (PPC), as amostras foram pesadas e submetidas a cozimento em forno préaquecido a $170^{\circ} \mathrm{C}$, até que a temperatura interna das amostras atingisse $71^{\circ} \mathrm{C}$ (30 minutos). $\mathrm{Na}$ sequência, foi determinada a força de cisalhamento (FC), conforme metodologia descrita por (Wheeler et al., 1995), utilizando-se um texturômetro (G-R Manufacturing Co, modelo 3000) equipado com uma lâmina de aço inox tipo Warner-Bratzler, sendo expressa em $\mathrm{kgf} / \mathrm{cm}^{2}$.

Os teores de umidade, cinzas e proteína foram determinados conforme metodologia descrita pela AOAC (Official..., 2000), nos artigos 985.41; 920.153 e 928.08, respectivamente. Os lipídeos totais foram extraídos de acordo com a metodologia descrita por Folch et al., (1957), por meio da extração com a solução clorofórmio:metanol $(2: 1), \quad$ seguida pela evaporação do solvente em estufa a $105^{\circ} \mathrm{C}$.

O experimento foi aprovado pelo Comitê de Ética sobre o Uso de Animais - Ceua - CBiotec da Universidade Federal da Paraíba (UFPB), com protocolo $\mathrm{n}^{\circ} 0203 / 14$.

Os dados foram submetidos à análise de variância (ANOVA), e as médias comparadas pelo teste de Tukey a 5\%. No estudo das correlações (CORR), foi usado o nível de significância de $5 \%$ e para melhor explicar as (co)variações entre essas características, utilizando-se o programa de análise estatística SAS (2009).

\section{RESULTADOS E DISCUSSÃO}

A dieta influenciou a força de cisalhamento (FC) da carne, sendo aquela com silagem de sorgo BRS 655 (Tab. 2) a que promoveu a menor média $(2,10 \mathrm{kgf})$ para esse parâmetro, indicando uma menor resistência à mastigação. $\mathrm{O} \mathrm{pH}$, a luminosidade $\left(\mathrm{L}^{*}\right)$, a intensidade de vermelho $\left(a^{*}\right)$, a intensidade de amarelo $\left(b^{*}\right)$ e a perda por cocção (PPC) não foram influenciados pelas dietas. 
Tabela 2. Valores médios das características físicas e composição centesimal da carne de cordeiros SPRD, alimentados com dietas contendo silagem de diferentes cultivares de sorgo

\begin{tabular}{|c|c|c|c|c|c|c|c|}
\hline \multirow[b]{2}{*}{ Parâmetros } & \multicolumn{5}{|c|}{ Silagens de sorgo } & \multirow[b]{2}{*}{$\mathrm{P}$} & \multirow[b]{2}{*}{$\mathrm{CV}(\%)$} \\
\hline & BRS 610 & BRS 655 & BRS 800 & BRS 810 & $\begin{array}{l}\text { Ponta } \\
\text { Negra }\end{array}$ & & \\
\hline${ }^{1} \mathrm{CMS}$ & 916,82 & 1050,96 & 1027,66 & 1041,07 & 981,31 & 0,271 & 9,55 \\
\hline${ }^{2} \mathrm{NDT}$ & 595,00 & 624,47 & 654,03 & 659,84 & 592,62 & 0,426 & 9,29 \\
\hline${ }^{3} \mathrm{GPT}(\mathrm{kg})$ & 8,343 & 8,657 & 8,371 & 8,473 & 8,433 & 0,973 & 17,26 \\
\hline $\mathrm{pH} 0 \mathrm{~h}$ & 6,83 & 6,70 & 6,80 & 6,84 & 6,80 & 0,960 & 2,83 \\
\hline $\mathrm{pH} 24 \mathrm{~h}$ & 5,62 & 5,65 & 5,63 & 5,61 & 5,69 & 0,650 & 3,66 \\
\hline COR L* & 22,02 & 22,45 & 20,03 & 21,34 & 20,80 & 0,218 & 8,33 \\
\hline$a^{*}$ & 18,65 & 18,30 & 18,67 & 18,37 & 18,62 & 0,560 & 8,84 \\
\hline$b^{*}$ & 16,09 & 16,63 & 15,29 & 16,18 & 15,73 & 0,309 & 7,80 \\
\hline${ }^{4} \mathrm{PPC} \%$ & 34,13 & 34,63 & 33,81 & 34,47 & 34,40 & 0,338 & 13,64 \\
\hline${ }^{5} \mathrm{FC}(\mathrm{kgf})$ & $2,77 \mathrm{a}$ & $2,10 \mathrm{~b}$ & $2,52 \mathrm{a}$ & $2,50 \mathrm{a}$ & $2,73 a$ & 0,034 & 17,99 \\
\hline Umidade (\%) & 72,50 & 72,28 & 72,22 & 72,78 & 72,89 & 0,809 & 1,63 \\
\hline Cinzas $(\%)$ & 1,06 & 1,06 & 1,13 & 1,10 & 1,11 & 0,498 & 4,74 \\
\hline Proteína (\%) & 23,33 & 23,62 & 24,40 & 24,72 & 24,32 & 0,268 & 7,35 \\
\hline Lipídeos (\%) & 3,08 & 2,97 & 2,60 & 2,98 & 3,34 & 0,215 & 44,82 \\
\hline
\end{tabular}

Letras distintas na mesma linha diferem pelo teste de Tukey a $5 \%$.

${ }^{1} \mathrm{CMS}=$ consumo de matéria seca $(\mathrm{g} / \mathrm{dia}) ;{ }^{2} \mathrm{NDT}=$ nutrientes digestíveis totais $(\mathrm{g} / \mathrm{dia}) ;{ }^{3} \mathrm{GPT}=$ ganho de peso total $(\mathrm{kg})$.

${ }^{4} \mathrm{PPC}=$ perdas de peso por cocção; ${ }^{5} \mathrm{FC}=$ força de cisalhamento.

Os valores de $\mathrm{pH}$ da carne dos cordeiros deste trabalho encontraram-se em torno de 5,64 (Tab. 2), resultado esse desejável, pois está próximo da faixa considerada normal para carne ovina que, segundo Gama et al. (2009), varia de 5,5 a 5,8 para $\mathrm{pH}$ após $24 \mathrm{~h}$. Além disso, tais valores indicam a inexistência de estresse pré-abate, uma vez que a pouca susceptibilidade ao estresse pela espécie ovina acarreta queda do $\mathrm{pH}$ dentro dos valores normais, comprovando, com isso, que a transformação do músculo em carne ocorreu como esperado.

As dietas não influenciaram $(\mathrm{P}>0,05)$ as variáveis de luminosidade e intensidade de vermelho e amarelo nas amostras de carne de cordeiros. Diversos autores citam valores superiores a 30,0 para a luminosidade da carne ovina (Madruga et al., 2008; Pinheiro et al., 2009; Vieira et al., 2010; Leão et al., 2012). As médias verificadas neste estudo foram inferiores a esse valor, o que permite afirmar que a carne avaliada era mais escura que as estudadas por esses autores, com médias variando entre 20,80 e 22,45 .

A intensidade de vermelho $\left(a^{*}\right)$ da carne de cordeiros não foi afetada pela dieta, variando entre 18,30 e 18,67. Dentre os fatores que mais influenciam a cor da carne, destacam-se a concentração de mioglobina, o tipo de fibra muscular, os manejos pré e pós-abate e o $\mathrm{pH}$. Segundo Jacob et al. (2012), carnes com potencial hidrogeniônico alto apresentam coloração mais escura devido à maior absorção da luz, pois há um aumento da atividade da citocromo-oxidase, que reduz as possibilidades de captação de oxigênio, e, portanto, há predomínio da mioglobina de cor vermelhopúrpura. $\mathrm{O}$ valor de $\mathrm{b}^{*}$ verificado neste estudo não foi afetado pelas dietas, com valores entre 15,29 e 16,63. Leão et al. (2012) citam que dietas com baixo teor de carotenoides, como grãos, feno e silagem, propiciam redução da cor amarela da gordura da carne, em razão da diluição da cor da gordura. Reportaram ainda que a intensidade da absorção de luz pelo carotenoide armazenado na gordura de cordeiros em confinamento é negativamente correlacionada ao período de confinamento, o que comprova que esse efeito é mediado pela diluição da gordura de coloração branca.

O resultado da perda de peso por cocção (PPC) encontrado nesta pesquisa variou de 29,48 e $34,63 \%$ e foi semelhante $(\mathrm{P}<0,05)$ entre os tratamentos. Em geral, os principais fatores que influenciam a perda de peso por cocção são: o método de transferência de calor da superfície e a temperatura interna da carne, pois afetam a quantidade de encolhimento do tecido conectivo, por meio da expulsão de fluidos da carne e da desnaturação das proteínas do músculo mediante a perda da capacidade de retenção da água. 
A dieta contendo silagem de sorgo BRS 655 (granífero) proporcionou uma carne mais macia, com valor de $2,10 \mathrm{kgf} / \mathrm{cm}^{2}$. Essa maior maciez é possivelmente decorrente do maior consumo desse genótipo pelos animais, que se associa à maior deposição de gordura intermuscular e, portanto, à maior facilidade de rompimento dos sarcômeros e das fibras da carne.

De acordo com Alves et al. (2008), animais terminados em dietas ricas em grãos apresentam maior porcentagem de gordura e marmoreio, o que proporciona maior maciez, suculência e sabor à carne. Foi observado, no presente trabalho, que os animais que receberam dietas de silagens de sorgo granífero BRS 655 apresentaram maior consumo $(1050,96 \mathrm{~g} / \mathrm{dia}) \mathrm{e}$ ganho de peso $(8,657 \mathrm{~kg})$ em relação aos demais e, assim, as carnes mostraram-se mais macias.

Cezar e Sousa (2007) consideram que os filetes de carne que não resistirem ao corte sob pressão menor que $2,27 \mathrm{kgf} / \mathrm{cm}^{2}$ indicam que a carne é macia; se resistirem a $2,27-3,63 \mathrm{kgf} / \mathrm{cm}^{2}$, a carne é considerada com maciez mediana; se resistirem à pressão acima de $3,63 \mathrm{kgf} / \mathrm{cm}^{2}$, considera-se carne dura; e se passarem de $5,44 \mathrm{kgf} / \mathrm{cm}^{2}$, a carne é tida como extremamente dura. As amostras analisadas no presente estudo apresentaram cisalhamento entre 2,10 $2,99 \mathrm{kgf} / \mathrm{cm}^{2}$, sendo consideradas macias e de maciez mediana, de acordo com a classificação supracitada.

Observa-se que a dieta não afetou $(\mathrm{P}>0,05)$ os percentuais de umidade, proteína, cinzas e lipídeos avaliados na carne, resultando em valores médios de 72,53, 24,08, 1,09 e 2,99\%, respectivamente (Tab. 2). Isso ocorreu provavelmente devido ao fato de as composições químicas das dietas serem semelhantes. De acordo com Madruga et al. (2008), a composição química da carne ovina apresenta valores médios de $75 \%$ de umidade, $23 \%$ de proteína, $4 \%$ de gordura e $1,1 \%$ de matéria mineral, sendo muito influenciada pela alimentação e pelo acabamento dos animais. Os teores encontrados neste estudo condizem com esses resultados.

$\mathrm{Na}$ carne destinada ao consumo, o teor de umidade no momento da mastigação traduz sensação de suculência e maciez ao consumidor. No presente estudo, a umidade não foi influenciada pelas dietas, apresentando valor médio de 72,53\%. Resultados obtidos por Pinheiro et al. (2009), os quais avaliaram cordeiros terminados em confinamento, constataram que as dietas utilizadas não influenciaram os valores de umidade do músculo estudado, encontrando-se média de $74,05 \%$ de umidade, condizentes, portanto, com os resultados deste estudo.

O percentual de cinzas ficou entre 1,06 - 1,13\%, portanto não sofreu influência do alimento utilizado $(\mathrm{P}>0,05)$. Nos tecidos cárneos, esse valor encontra-se ao redor de $1 \%$ e varia pouco, independentemente da dieta. $\mathrm{O}$ valor médio de proteína verificado entre os tratamentos ficou ao redor de $24,08 \%$, superior aos valores relatados por Santos et al. (2008), que obtiveram valores que variaram entre $19,08 \%$ e $21,06 \%$ de proteína, ao avaliarem a carne de cordeiros Santa Inês e Bergamácia, que são animais especializados para produção de carne.

$\mathrm{O}$ teor de gordura encontrado no presente trabalho variou entre 2,60 e 3,34, podendo ser a carne considerada magra, de acordo com Leão et al. (2011), por ter menos de 5\% de gordura. Isso indica a possibilidade de uso das silagens estudadas como estratégia nutricional, haja vista que elas não aumentam a proporção de gordura na carne, o que é altamente desejável sob o ponto de vista alimentar do consumidor.

Osório et al. (2013) afirmaram que a idade também influencia no teor de gordura, pois, como os animais eram jovens, aproximadamente oito meses de idade no abate, apresentavam menos gordura em sua composição muscular, uma vez que os nutrientes ingeridos são convertidos na formação da sua estrutura física, de ossos e tecidos. Essa concentração para o teor de lipídeos pode ser considerada um ponto positivo, diante da busca dos consumidores por alimentos com baixos teores de gordura.

Para avaliar o grau de associação entre os atributos físico-químicos e nutricionais da carne de cordeiros sem padrão racial definido, alimentados com dietas contendo silagens de diferentes cultivares de sorgo, procedeu-se à análise de correlação de Pearson, considerandose todas as informações independentes das fontes de variação (Tab. 3). 
Tabela 3. Coeficientes de correlação de Pearson (r) entre parâmetros físicos de cor $\left(L^{*}, a^{*}, b^{*}\right)$, força de cisalhamento (FC), perda de peso por cocção (PPC) e parâmetros químicos de lipídeos (Lip), umidade (U), cinzas (C) e proteína (Ptn) da carne de cordeiros SPRD, alimentados com dietas contendo silagem de diferentes cultivares de sorgo

\begin{tabular}{ccccccccc}
\hline Variáveis & $\mathrm{a}^{*}$ & $\mathrm{~b}^{*}$ & $\mathrm{FC}$ & $\mathrm{PPC}$ & $\mathrm{Lip}$ & $\mathrm{U}$ & $\mathrm{C}$ & Ptn \\
\hline $\mathrm{L}^{*}$ & $0,991^{* *}$ & $0,973^{* *}$ & $0,628^{* *}$ & $0,877^{* *}$ & 0,175 & $-0,082$ & 0,021 & 0,083 \\
$\mathrm{a}^{*}$ & - & $0,977^{* *}$ & $0,599^{* *}$ & $0,844^{* *}$ & 0,173 & $-0,115$ & 0,036 & 0,114 \\
$\mathrm{~b}^{*}$ & & - & $0,631^{* *}$ & $0,846^{* *}$ & 0,154 & $-0,095$ & 0,009 & 0,177 \\
FC & & & - & $0,712^{* *}$ & 0,044 & $-0,091$ & $0,312^{*}$ & 0,288 \\
PPC & & & & - & 0,139 & 0,030 & 0,131 & 0,185 \\
Lip & & & & & - & 0,200 & 0,026 & $-0,167$ \\
U & & & & & & - & $-0,327$ & 0,101 \\
C & & & & & & & - & 0,250 \\
Ptn & & & & & & & & \\
\hline ns $(\mathrm{P}>0,05) ;{ }^{*}(\mathrm{P}<0,05) ; *(\mathrm{P}<0,01)$.
\end{tabular}

O componente da cor $b^{*}$ apresentou correlação positiva moderada $(\mathrm{r}=0,631)$ com a força de cisalhamento. Como o teor de amarelo $\left(b^{*}\right)$ está relacionado à coloração da gordura, então, maiores níveis de gordura intra e intermuscular conduzem a menores perdas de peso por coç̧ão e à obtenção de carnes mais macias e suculentas, visto que a gordura presente na carne atua como barreira contra a perda de umidade (Costa et al., 2011).

A perda de peso por cocção manteve uma correlação positiva com os componentes da cor $\left(L^{*}, a^{*}, b^{*}\right)$ e com a força de cisalhamento $(\mathrm{r}=0,877,0,844,0,846$ e 0,712 , respectivamente), indicando que a textura e a cor da carne são alteradas pelo seu teor de umidade. Com o desenvolvimento do animal, este irá apresentar cor mais intensa da carne, já que a concentração do pigmento mioglobina no músculo Longissimus dorsi se incrementa com a idade. O depósito de gordura aumenta e a quantidade de água presente no músculo diminui, resultando em uma menor intensidade luminosa e em uma carne mais macia.

Percebeu-se correlação positiva entre os componentes da cor, sendo que $\mathrm{L}^{*}$ correlacionou-se positivamente com a* e $\mathrm{b}^{*}$, $\mathrm{r}=0,991$, e $\mathrm{r}=0$, 973, respectivamente, o que sugere que os tecidos com maior intensidade de cor (vermelho e amarelo) apresentaram também maior luminosidade.

Força de cisalhamento e cinzas apresentaram correlação fraca $(\mathrm{r}=0,312)$, indicando que, a alimentação recebida pelos animais foi direcionada para a formação de tecidos. Enquanto o animal cresce e se desenvolve, a concentração de água diminui e a proporção de cinzas e proteínas se eleva até atingirem valores constantes.

\section{CONCLUSÃO}

$O$ uso de diferentes cultivares de sorgo na terminação de cordeiros não interfere na qualidade química e física da carne, exceto para o parâmetro de maciez, visto que a dieta contendo silagem do cultivar de sorgo BRS 655 proporcionou uma carne mais macia.

\section{REFERÊNCIAS}

ALVES, D.D. et al. Maciez da carne bovina. Ciênc. Anim. Bras., v.6, p.135-149, 2008.

CEZAR, M.F.; SOUSA, W.H. Carcaças ovinas e caprinas: obtenção, avaliação e classificação. Uberaba: Agropecuária Tropical, 2007. 147p.

COSTA, R.G. et al. Composição centesimal e análise sensorial da carne de ovinos Morada Nova alimentados com dietas contendo melão em substituição ao milho. Rev. Bras. Zootec., v.40, p.2799-2804, 2011.

FOLCH, J. et al. A simple method for the isolation and purification of total lipids from animal tissues. J. Biol. Chem., v.226, p.497-509, 1957.

GAMA, K.V.M.F. et al. Características físicoquímicas da carne ovina comercializada no município de Pombal - PB - Brasil. Rev. Verde Agroecol. Desenv. Susten., v.4, p.131-134, 2009. 
JACOB, R.H.; THOMSON, K.L. The importance of chill rate when characterizing colour change of lamb meat during retail display. Meat Sci., v.90, p.478-484, 2012.

LEÃO, A.G. et al. Características físicoquímicas e sensoriais da carne de cordeiros terminados com dietas contendo cana-de-açúcar ou silagem de milho $\mathrm{e}$ dois níveis de concentrado. Rev. Bras. Zootec., v.4, p.12531262, 2012.

LEÃO, A.G. et al. Características nutricionais da carne de cordeiros terminados com dietas contendo cana-de-açúcar ou silagem de milho e dois níveis de concentrado. Rev. Bras. Zootec., v.40, p.1072-1079, 2011.

MACHADO, F.S. et al. Consumo e digestibilidade aparente de silagens de sorgo em diferentes estádios de maturação. Arq. Bras. Med. Vet. Zootec., v.63, p.1470-1478, 2011.

MADRUGA, M.S. et al. Efeito de dietas com níveis crescentes de caroço de algodão integral sobre a composição química e o perfil de ácidos graxos da carne de cordeiros Santa Inês. Rev. Bras. Zootec., v.37, p.1496-1502, 2008.

NUTRIENT requeriments of small ruminants. 7.ed. Washington, DC: National Academic Press, 2007. 408p.

OFFICIAL methods of analysis. 17.ed. Washington, DC: AOAC, 2000. 2200p.

OSÓRIO, M.T.M. et al. Características sensoriais da carne de ovinos Corriedale em função da idade de abate e da castração. Rev. Agrar., v.6, p.60-66, 2013.
PINHEIRO, R.S.B. et al. Qualidade da carne de cordeiros confinados recebendo diferentes relações de volumoso: concentrado na dieta. Ciênc. Tecnol. Aliment., v.29, p.407-411, 2009.

PRECISE color communication - color control from perception to instrumentation. Osaka: Minolta Co., 1998. 59p.

SANTOS, C.L. et al. Análise centesimal dos cortes da carcaça de cordeiros Santa Inês e Bergamácia. Ciênc. Tecnol. Aliment., v.28, p.5159, 2008.

SAS user's guide. Version.9.2 Cary: SAS Institute, 2009.

SNIFFEN, C.J. et al. A net carbohydrate and protein system for evaluating cattle diets: II. Carbohydrate and protein availability. J. Anim. Sci., v.70, p.3562-3577, 1992.

TEJEDA, J.F. et al. Effect of live weight and sex on physicochemical and sensorial characteristics of Merino lamb meat. Meat Sci., v.80, p.10611067, 2008.

VIEIRA, T.R.L. et al. Propriedades físicas e sensoriais da carne de cordeiros Santa Inês terminados em dietas com diferentes níveis de caroço de algodão integral (Gossypium hirsutum). Ciênc. Tecnol. Aliment., v.30, p.372$377,2010$.

WHEELER, T.L. et al. Standardized warner bratzler shear force procedures for meat tenderness measurement. Clay Center: Marc USDA, 1995. 7p. 